\title{
Application of Thermochemical Energy Hazard Criteria to the Prediction of Lower Flammability Limits of Hydrocarbons in Air
}

\author{
D. Dalmazzone' ${ }^{1}$ J.C. Laforest ${ }^{2}$ and J.M. Petit ${ }^{2}$ \\ 1 Laboratoire chimie et procédés, École nationale supérieure de techniques avancées, Chemin de la Hunière, 91761 Palaiseau Cedex - France \\ 2 Institut national de recherche et de sécurité, 30, rue Olivier-Noyer, 75680 Paris Cedex 14 - France \\ e-mail: dalmazzo@enstay.ensta.fr
}

\begin{abstract}
Résumé - Application de critères thermochimiques de danger d'explosion thermique à la prédiction des limites inférieures d'inflammabilité des hydrocarbures dans l'air - Les critères de danger d'explosion thermique développés dans le programme CHETAH de l'ASTM ont été appliqués comme critères d'inflammabilité des vapeurs d'hydrocarbures mélangées à l'air, à des concentrations proches de la limite inférieure d'inflammabilité. Nous proposons d'utiliser ces critères pour le calcul prédictif des limites inférieures d'inflammabilité des hydrocarbures dans l'air, sous pression atmosphérique et à température ambiante. Une analyse statistique portant sur 67 molécules combustibles a permis de déterminer que le quatrième critère CHETAH conduit aux meilleures estimations. La méthode proposée est prédictive, l'ensemble des données d'entrée pouvant être obtenues par une méthode de contribution de groupe. Elle est fiable, les limites prédites étant majoritairement sousévaluées de $0,11 \mathrm{~mol} \%$ en moyenne. La méthode est également précise, l'écart type des estimations ne dépassant pas $0,14 \mathrm{~mol} \%$. Enfin, la méthode s'applique de la même manière aux mélanges de combustibles, et donne les mêmes résultats que la loi de Le Chatelier.
\end{abstract}

Mots-clés : limite d'inflammabilité, hydrocarbures, prédiction, CHETAH.

\begin{abstract}
Application of Thermochemical Energy Hazard Criteria to the Prediction of Lower Flammability Limits of Hydrocarbons in Air - The energy hazard criteria of ASTM program CHETAH have been tested as criteria of flammability of gaseous mixtures containing an hydrocarbon vapour and air as oxidiser, at lean concentrations. A method for calculating the lower flammability limits in air, at atmospheric pressure and ambient temperature, is proposed as a result of a statistical study, which involved 67 combustible compounds. CHETAH's fourth energy hazard criterion was found to be the most reliable flammability criterion. The method is predictive since all the input data may be obtained with very good accuracy using a group contribution method. It is reliable, predicted limits being more frequently underevaluated, by $0.11 \mathrm{~mol} \%$ on average, than overevaluated. The method is also precise, with a standard deviation of the estimates of $0.14 \mathrm{~mol} \%$. It is easily applicable to fuel mixtures and gives the same results as Le Chatelier's law.
\end{abstract}

Keywords: flammability limit, hydrocarbons, prediction, CHETAH. 


\section{INTRODUCTION}

Flammability is defined as the capability of a gas mixture to unlimitedly sustain the autonomous propagation of a flame. Generally, a fuel-oxidiser mixture is only flammable within a limited range of compositions. The minimum and maximum fuel concentration limits of this range are known as the lower and upper flammability limits, respectively. They are expressed in fuel mole percent in the total mixture. Flammability limits are properties of a particular fuel and oxidiser couple, and also depend on temperature and pressure conditions. The most frequently used are flammability limits in air, at ambient temperature and atmospheric pressure. The most useful for safety purposes is the lower flammability limit, which indicates the fuel vapour concentration that should not be exceeded, in order to avoid any explosion hazard.

Flammability limits are important data in the field of fire and explosion prevention, in any human activity handling potentially flammable substances. Unfortunately, very few among the thousands of chemicals produced by the industry have their flammability limits known precisely. Measuring flammability limits is an expensive and time-consuming process, especially when good accuracy has to be achieved, because flame propagation in very lean compositions is largely dependent on experimental conditions. The values available are therefore highly subject to uncertainties.

It is thus interesting to develop a computational method to evaluate the flammability limits of a wide variety of organic compounds in air, with an accuracy comparable to the experimental methods, and if possible with total predictability. Several methods of prediction using empirical correlations between the fuel's chemical structure and the flammability limits have been proposed by Zabetakis (1965), Shimy (1970), or Hilado (1975), Hilado and Cumming (1979). Other authors, such as Shebeko et al. (1983), have proposed some group contribution methods. All these methods involve some parameters which depend on the chemical nature of the combustible. Since only limited sets of parameters have been published, most of these methods have a restricted field of application.

Ducros et al. (1981) proposed an original application of ASTM (American Society for Testing and Materials) computer program CHETAH (Chemical Thermodynamics and Energy Hazard Evaluation program) (Seaton et al., 1974). CHETAH uses thermochemical criteria to predictively evaluate the explosion potential hazard of a compound or a mixture of organic compounds. The idea was that criteria originally intended to predict the explosiveness of solid or liquid compounds could also be used as flammability criteria for gaseous mixtures. Some encouraging results were published, even though the method needed further optimisation, and many uncertainties remained about the application range (Ducros and Sannier, 1988).

\section{THE ENERGY HAZARD CRITERIA OF CHETAH}

CHETAH was developed by the ASTM to evaluate the potential explosion hazard of pure substances and mixtures, using four predictive criteria based on thermochemical properties (Seaton et al., 1974). The criteria provide a thermal hazard rating based upon correlations evidenced by statistical studies.

The criteria, and the equations used to compute them in the case of lean fuel-air mixtures, are described in the following.

\subsection{First Criterion: $\mathrm{Cl}$}

For the first criterion, CHETAH uses the enthalpy $\Delta H_{\max }$, in kilocalories per gram of mixture, of the most exothermic reaction that could occur, given the composition of the reacting mixture.

- If $0>\Delta H_{\max }>-0.3 \mathrm{kcal} / \mathrm{mol}$, the thermal potential hazard is rated as low.

- If $-0.3>\Delta H_{\max }>-0.7 \mathrm{kcal} / \mathrm{mol}$, it is rated as medium.

- If $\Delta H_{\max }<-0.7 \mathrm{kcal} / \mathrm{mol}$, it is rated as high.

The only input data required to compute $\Delta H_{\max }$ are the enthalpies of formation of all the reactants in the gas phase, and the final composition having the lowest possible enthalpy, given the overall elemental composition. The unknown enthalpies of formation are calculated using Benson's group contribution method (Benson, 1976). The enthalpies of formation of all possible products are included in a data bank. A linear programming method is used to minimise the final enthalpy.

\subsection{Second Criterion: $\mathbf{C}$}

The second criterion uses the difference between the heat of combustion of the reactants in an excess of oxygen $\Delta H_{c}$ and the maximum heat of reaction $\Delta H_{\max }$ defined above: $\Delta H_{c}-\Delta H_{\max }$, in kilocalories per gram.

- If $\Delta H_{c}-\Delta H_{\max }>5 \mathrm{kcal} / \mathrm{mol}$, the thermal potential hazard is rated as low.

- If $5>\Delta H_{c}-\Delta H_{\max }>2 \mathrm{kcal} / \mathrm{mol}$, it is rated as medium.

- If $2>\Delta H_{c}-\Delta H_{\text {max }}>0 \mathrm{kcal} / \mathrm{mol}$, it is rated as high.

In the case of lean fuel-air mixtures, $C 2$ has no meaning because the combustion is the most exothermic possible reaction, and $\Delta H_{c}-\Delta H_{\max }$ would always be zero. Therefore, we did not use this criterion in this study.

\subsection{Third Criterion: C3}

The third criterion is based on the oxygen balance of the mixture, in gram percent:

$$
O B=\left(n_{\mathrm{O}}-2 n_{\mathrm{C}}-\frac{n_{\mathrm{H}}}{2}\right) \frac{16}{M} \times 100 \%
$$


- If $O B>160 \%$ or $O B<-240 \%$, the thermal potential hazard is rated as low.

- If $-120 \%<O B<-240 \%$ or $80 \%<O B<160 \%$, it is rated as medium.

- If $-120 \%<O B<80 \%$, it is rated as high.

C3 was tested for flammability limit prediction, but gave poor results (Ducros and Sannier, 1988; Dalmazzone, 1995) which will not be reported here.

\subsection{Fourth Criterion: $C 4$}

$C 4$ is represented by the empirical function:

$$
C 4=10 \cdot \Delta H_{\max }^{2} \frac{M}{n}
$$

where $\Delta H_{\max }$ is the same maximum energy of reaction as used in the computation of $C 1$ and $C 2, n$ is the number of gram-atoms contained in a mass $M$ of the reacting mixture.

- If $C 4<30 \mathrm{kcal}^{2} \cdot \mathrm{g}$, the thermal potential hazard is rated as low.

- If $30<C 4<110 \mathrm{kcal}^{2} \cdot \mathrm{g}$, it is rated as medium.

- If $C 4>110 \mathrm{kcal}^{2} \cdot \mathrm{g}$, it is rated as high.

\subsection{Application to Near-Limit Mixtures}

We define those fuel-air mixtures that have a fuel mole fraction close to the lower flammability limit, at $25^{\circ} \mathrm{C}$ and atmospheric pressure, as near-limit mixtures. We considered that the most exothermic reaction that could take place in that case was the total combustion of the fuel, leaving the excess oxidiser unchanged. Thus, the computation of CHETAH thermal hazard criteria is particularly easy. Let the fuel's formula be $\mathrm{C}_{a} \mathrm{H}_{b}$. Its molecular weight is: $M_{F}=12 a+b$, and it contains $n_{F}=a+b$ gram-atoms per mole. We assume that air is composed of $21 \%$ oxygen and $79 \%$ nitrogen, has a molecular weight of $28.84 \mathrm{~g} \cdot \mathrm{mol}^{-1}$, and contains 2 gramatoms per mole. The reaction equation is:

$$
\begin{aligned}
& \mathrm{C}_{a} \mathrm{H}_{b}+\frac{1}{2}\left(2 a+\frac{b}{2}\right)\left(\mathrm{O}_{2}+\frac{0.79}{0.21} \mathrm{~N}_{2}\right)(+ \text { excess air }) \rightarrow \\
& a \mathrm{CO}_{2}+\frac{b}{2} \mathrm{H}_{2} \mathrm{O}+\left[\frac{1}{2}\left(2 a+\frac{b}{2}\right) \frac{0.79}{0.21}\right] \mathrm{N}_{2} \text { (+ excess air) }
\end{aligned}
$$

As the reaction takes place at atmospheric pressure, its enthalpy is equal to the standard enthalpy of combustion. For one mole of fuel, it is given by:

$$
\Delta_{c}^{0} H=a \Delta_{f}^{0} H\left(\mathrm{CO}_{2}\right)+\frac{b}{2} \Delta_{f}^{0} H\left(\mathrm{H}_{2} \mathrm{O}\right)-\Delta_{f}^{0} H(F)
$$

where $\Delta_{f}^{0} H(F), \Delta_{f}^{0} H\left(\mathrm{CO}_{2}\right)$ and $\Delta_{f}^{0} H\left(\mathrm{H}_{2} \mathrm{O}\right)$ stand for the standard enthalpies of formation of the fuel, and of the combustion products, respectively.

Criterion $C 1$ is equal to the enthalpy of combustion of $1 \mathrm{~g}$ of fuel-air mixture. If $x$ is the mole fraction of the fuel in the mixture, it is given by:

$$
C 1=\frac{x \Delta_{c}^{0} H}{x M_{F}+28.84(1-x)}
$$

And $C 4$ is given by:

$$
C 4=\frac{10\left(x \Delta_{c}^{0} H\right)^{2}}{\left(x M_{F}+28.84(1-x)\right)\left(x n_{F}+2(1-x)\right)}
$$

\section{STATISTICAL ANALYSIS}

\subsection{Experimental Data}

Our literature sources for flammability limit data were the bulletin 503 of the US Bureau of Mines (Coward and Jones, 1952), the handbook on explosive mixtures published by the French National Institute for Research and Safety (INRS) (Cleuet and Gros, 1989), and the Hazardous Chemical Data Book (Weiss, 1980).

In addition, we used values determined in our laboratory (Dalmazzone, 1995), using a specially designed apparatus, featuring several improvements from the device described by Coward and Jones (1952). The 67 test molecules selected are listed in Table 1.

The standard enthalpies of formation of carbon dioxide and water in the gaseous state, which are needed to compute the enthalpies of combustion, were found in the NBS (National Bureau of Standards) tables (Wagman et al., 1982):

$-\Delta_{f}^{0} H\left(\mathrm{CO}_{2}\right)=-94.051 \mathrm{kcal} \cdot \mathrm{mol}^{-1}$

$-\Delta_{f}^{0} H\left(\mathrm{H}_{2} \mathrm{O}\right)=-57.796 \mathrm{kcal} \cdot \mathrm{mol}^{-1}$

at $298 \mathrm{~K}$.

The standard enthalpies of formation of the fuels, $\Delta_{f}^{0} H(F)$, were mostly found in Pedley's Thermochemical Data of Organic Compounds (Pedley et al., 1986). When not available they were estimated using the Benson's method, the group contributions being taken from a data base available at the laboratory (Dalmazzone, 1995), that considerably extends original Benson's one.

\subsection{Principle of the Analysis}

Criteria $C 1$ and $C 4$ have been expressed in Equations (1) and (2) as functions of the fuel mole fraction in the mixture $x$. Each of these functions is defined within the interval $x=0$ 
TABLE 1

Flammability limit estimation results for the 67 test molecules used in the study

\begin{tabular}{|c|c|c|c|c|c|c|c|}
\hline \multirow[b]{2}{*}{ Formula } & \multirow[b]{2}{*}{ Name } & \multirow[b]{2}{*}{$\mathbf{S}$} & \multirow[b]{2}{*}{$\operatorname{Exp}$} & \multicolumn{2}{|c|}{$C 1$} & \multicolumn{2}{|c|}{$C 4$} \\
\hline & & & & Pred & Err & Pred & Err \\
\hline $\mathrm{CH}_{4}$ & Methane & 1 & 5.00 & 5.07 & +0.07 & 4.99 & -0.01 \\
\hline $\mathrm{C}_{2} \mathrm{H}_{6}$ & Ethane & 1 & 3.00 & 2.92 & -0.08 & 2.85 & -0.15 \\
\hline $\mathrm{C}_{2} \mathrm{H}_{4}$ & Ethylene & 1 & 3.05 & 3.14 & +0.09 & 3.04 & -0.01 \\
\hline $\mathrm{C}_{2} \mathrm{H}_{2}$ & Acetylene & 1 & 2.50 & 3.30 & +0.80 & 3.15 & +0.65 \\
\hline $\mathrm{C}_{3} \mathrm{H}_{8}$ & Propane & 1 & 2.15 & 2.06 & -0.09 & 2.01 & -0.14 \\
\hline $\mathrm{C}_{3} \mathrm{H}_{6}$ & Cyclopropane & 1 & 2.40 & 2.15 & -0.25 & 2.07 & -0.33 \\
\hline $\mathrm{C}_{3} \mathrm{H}_{6}$ & Propene & 1 & 2.40 & 2.18 & -0.22 & 2.11 & -0.29 \\
\hline $\mathrm{C}_{4} \mathrm{H}_{10}$ & Butane & 1 & 1.85 & 1.59 & -0.26 & 1.55 & -0.30 \\
\hline $\mathrm{C}_{4} \mathrm{H}_{10}$ & Methylpropane & 1 & 1.83 & 1.60 & -0.23 & 1.55 & -0.28 \\
\hline $\mathrm{C}_{4} \mathrm{H}_{8}$ & 1-Butene & 1 & 1.65 & 1.66 & +0.01 & 1.61 & -0.04 \\
\hline $\mathrm{C}_{4} \mathrm{H}_{8}$ & cis-2-Butene & 1 & 1.85 & 1.67 & -0.18 & 1.61 & -0.24 \\
\hline $\mathrm{C}_{4} \mathrm{H}_{8}$ & trans-2-Butene & 1 & 1.85 & 1.66 & -0.19 & 1.61 & -0.24 \\
\hline $\mathrm{C}_{4} \mathrm{H}_{8}$ & Methylpropene & 1 & 1.78 & 1.68 & -0.10 & 1.62 & -0.16 \\
\hline $\mathrm{C}_{4} \mathrm{H}_{6}$ & 1,3-Butadiene & 1 & 2.00 & 1.75 & -0.25 & 1.69 & -0.31 \\
\hline $\mathrm{C}_{5} \mathrm{H}_{12}$ & Pentane & 1 & 1.42 & 1.30 & -0.12 & 1.26 & -0.16 \\
\hline $\mathrm{C}_{5} \mathrm{H}_{12}$ & Dimethylpropane & 1 & 1.38 & 1.31 & -0.07 & 1.27 & -0.11 \\
\hline $\mathrm{C}_{5} \mathrm{H}_{12}$ & Methyl-2-Butane & 1 & 1.35 & 1.30 & -0.05 & 1.26 & -0.09 \\
\hline $\mathrm{C}_{5} \mathrm{H}_{10}$ & Cyclopentane & 2 & 1.50 & 1.37 & -0.13 & 1.32 & -0.18 \\
\hline $\mathrm{C}_{5} \mathrm{H}_{10}$ & 1-Pentene & 1 & 1.50 & 1.34 & -0.16 & 1.30 & -0.20 \\
\hline $\mathrm{C}_{5} \mathrm{H}_{10}$ & 2-Methyl-1-Butene & 2 & 1.50 & 1.35 & -0.15 & 1.31 & -0.19 \\
\hline $\mathrm{C}_{6} \mathrm{H}_{14}$ & Hexane & 1 & 1.18 & 1.09 & -0.09 & 1.06 & -0.12 \\
\hline $\mathrm{C}_{6} \mathrm{H}_{14}$ & 2,2-Dimethylbutane & 1 & 1.20 & 1.10 & -0.10 & 1.07 & -0.13 \\
\hline $\mathrm{C}_{6} \mathrm{H}_{14}$ & 2,3-Dimethylbutane & 1 & 1.20 & 1.10 & -0.10 & 1.07 & -0.13 \\
\hline $\mathrm{C}_{6} \mathrm{H}_{14}$ & 2-Methylpentane & 1 & 1.18 & 1.10 & -0.08 & 1.06 & -0.12 \\
\hline $\mathrm{C}_{6} \mathrm{H}_{12}$ & Cyclohexane & 1 & 1.26 & 1.15 & -0.11 & 1.12 & -0.14 \\
\hline $\mathrm{C}_{6} \mathrm{H}_{12}$ & Methylcyclopentane & 2 & 1.00 & 1.15 & +0.15 & 1.11 & +0.11 \\
\hline $\mathrm{C}_{6} \mathrm{H}_{12}$ & Ethylcyclobutane & 1 & 1.24 & 1.12 & -0.12 & 1.09 & -0.15 \\
\hline $\mathrm{C}_{6} \mathrm{H}_{12}$ & 1-Hexene & 3 & 1.20 & 1.13 & -0.07 & 1.09 & -0.11 \\
\hline $\mathrm{C}_{6} \mathrm{H}_{6}$ & Benzol & 1 & 1.40 & 1.34 & -0.06 & 1.28 & -0.12 \\
\hline $\mathrm{C}_{7} \mathrm{H}_{16}$ & Heptane & 1 & 1.10 & 0.95 & -0.15 & 0.92 & -0.18 \\
\hline $\mathrm{C}_{7} \mathrm{H}_{16}$ & 2-Methylhexane & 2 & 1.00 & 0.95 & -0.05 & 0.92 & -0.08 \\
\hline $\mathrm{C}_{7} \mathrm{H}_{16}$ & 2,3-Dimethylpentane & 1 & 1.12 & 0.95 & -0.17 & 0.92 & -0.20 \\
\hline $\mathrm{C}_{7} \mathrm{H}_{14}$ & Methylcyclohexane & 1 & 1.25 & 0.99 & -0.26 & 0.96 & -0.29 \\
\hline $\mathrm{C}_{7} \mathrm{H}_{14}$ & Ethylcyclopentane & 1 & 1.10 & 0.99 & -0.11 & 0.95 & -0.15 \\
\hline $\mathrm{C}_{7} \mathrm{H}_{14}$ & 1-Heptene & 4 & 0.90 & 0.97 & +0.07 & 0.94 & +0.04 \\
\hline $\mathrm{C}_{7} \mathrm{H}_{8}$ & Tuluol & 2 & 1.20 & 1.13 & -0.07 & 1.08 & -0.12 \\
\hline $\mathrm{C}_{8} \mathrm{H}_{18}$ & Octane & 1 & 0.95 & 0.83 & -0.12 & 0.81 & -0.14 \\
\hline
\end{tabular}


TABLE 1

Flammability limit estimation results for the 67 test molecules used in the study (continued)

\begin{tabular}{|c|c|c|c|c|c|c|c|}
\hline \multirow[b]{2}{*}{ Formula } & \multirow[b]{2}{*}{ Name } & \multirow[b]{2}{*}{$\mathbf{S}$} & \multirow[b]{2}{*}{ Exp } & \multicolumn{2}{|c|}{$C 1$} & \multicolumn{2}{|c|}{$C 4$} \\
\hline & & & & Pred & Err & Pred & Err \\
\hline $\mathrm{C}_{8} \mathrm{H}_{18}$ & 2,2,4-Trimethylpentane & 1 & 1.15 & 0.84 & -0.31 & 0.81 & -0.34 \\
\hline $\mathrm{C}_{8} \mathrm{H}_{16}$ & Ethylcyclohexane & 1 & 0.95 & 0.87 & -0.08 & 0.84 & -0.11 \\
\hline $\mathrm{C}_{8} \mathrm{H}_{16}$ & 1-Octene & 3 & 0.90 & 0.85 & -0.05 & 0.83 & -0.07 \\
\hline $\mathrm{C}_{8} \mathrm{H}_{16}$ & 2,4,4-Trimethyl-1-Pentene & 3 & 0.90 & 0.86 & -0.04 & 0.83 & -0.07 \\
\hline $\mathrm{C}_{8} \mathrm{H}_{10}$ & 1,2-Dimethylbenzol & 1 & 1.00 & 0.98 & -0.02 & 0.94 & -0.06 \\
\hline $\mathrm{C}_{8} \mathrm{H}_{10}$ & 1,3-Dimethylbenzol & 2 & 1.10 & 0.98 & -0.12 & 0.94 & -0.16 \\
\hline $\mathrm{C}_{8} \mathrm{H}_{10}$ & 1,4-Dimethylbenzol & 2 & 1.10 & 0.98 & -0.12 & 0.94 & -0.16 \\
\hline $\mathrm{C}_{8} \mathrm{H}_{10}$ & Ethylbenzol & 1 & 0.99 & 0.97 & -0.02 & 0.93 & -0.06 \\
\hline $\mathrm{C}_{8} \mathrm{H}_{8}$ & Styrene & 1 & 1.10 & 1.00 & -0.10 & 0.96 & -0.14 \\
\hline $\mathrm{C}_{9} \mathrm{H}_{20}$ & Nonane & 1 & 0.83 & 0.74 & -0.09 & 0.72 & -0.11 \\
\hline $\mathrm{C}_{9} \mathrm{H}_{20}$ & 3,3-Diethylpentane & 1 & 0.74 & 0.75 & +0.01 & 0.72 & -0.02 \\
\hline $\mathrm{C}_{9} \mathrm{H}_{20}$ & 2,2,3,3-Tetramethylpentane & 1 & 0.77 & 0.75 & -0.02 & 0.72 & -0.05 \\
\hline $\mathrm{C}_{9} \mathrm{H}_{12}$ & 1-Phenylpropane & 2 & 0.80 & 0.86 & +0.06 & 0.82 & +0.02 \\
\hline $\mathrm{C}_{9} \mathrm{H}_{12}$ & 2-Phenylpropane & 2 & 0.90 & 0.86 & -0.04 & 0.82 & -0.08 \\
\hline $\mathrm{C}_{9} \mathrm{H}_{12}$ & 1,2,4-Trimethylbenzol & 2 & 0.90 & 0.86 & -0.04 & 0.83 & -0.07 \\
\hline $\mathrm{C}_{9} \mathrm{H}_{10}$ & $p$-Methylstyrene & 3 & 0.80 & 0.88 & +0.08 & 0.84 & +0.04 \\
\hline $\mathrm{C}_{10} \mathrm{H}_{22}$ & Decane & 1 & 0.77 & 0.67 & -0.10 & 0.65 & -0.12 \\
\hline $\mathrm{C}_{10} \mathrm{H}_{20}$ & 1,4-Diethylcyclohexane & 2 & 0.80 & 0.70 & -0.10 & 0.68 & -0.12 \\
\hline $\mathrm{C}_{10} \mathrm{H}_{18}$ & cis-Decalin & 3 & 0.70 & 0.72 & +0.02 & 0.70 & 0.00 \\
\hline $\mathrm{C}_{10} \mathrm{H}_{18}$ & trans-Decalin & 3 & 0.70 & 0.72 & +0.02 & 0.70 & 0.00 \\
\hline $\mathrm{C}_{10} \mathrm{H}_{16}$ & \pm Limonene & 2 & 0.70 & 0.73 & +0.03 & 0.70 & 0.00 \\
\hline $\mathrm{C}_{10} \mathrm{H}_{14}$ & 1-Phenylbutane & 1 & 0.82 & 0.76 & -0.06 & 0.73 & -0.09 \\
\hline $\mathrm{C}_{10} \mathrm{H}_{14}$ & 2-Phenylbutane & 2 & 0.78 & 0.76 & -0.02 & 0.73 & -0.05 \\
\hline $\mathrm{C}_{10} \mathrm{H}_{14}$ & p-Cymene & 2 & 0.70 & 0.77 & +0.07 & 0.74 & +0.04 \\
\hline $\mathrm{C}_{10} \mathrm{H}_{14}$ & 2-Methyl-1-Phenylpropane & 2 & 0.83 & 0.76 & -0.07 & 0.73 & -0.10 \\
\hline $\mathrm{C}_{10} \mathrm{H}_{14}$ & 2-Methyl-2-Phenylpropane & 2 & 0.84 & 0.76 & -0.08 & 0.73 & -0.11 \\
\hline $\mathrm{C}_{10} \mathrm{H}_{12}$ & Tetralin & 3 & 0.80 & 0.79 & -0.01 & 0.76 & -0.04 \\
\hline \multirow[t]{2}{*}{$\mathrm{C}_{10} \mathrm{H}_{12}$} & 3a,4,7,7a-Tetrahydro- & & & & & & \\
\hline & 4,7-Methano-1H-Indene & 3 & 0.80 & 0.77 & -0.03 & 0.73 & -0.07 \\
\hline $\mathrm{C}_{10} \mathrm{H}_{10}$ & 1,4-Divinylbenzene & 2 & 1.10 & 0.80 & -0.30 & 0.76 & -0.34 \\
\hline $\mathrm{C}_{10} \mathrm{H}_{8}$ & Naphthalene & 1 & 0.88 & 0.85 & -0.03 & 0.81 & -0.07 \\
\hline
\end{tabular}

The S column contains the source for experimental data:

1: Coward and Jones (1952)

2: Cleuet and Gros (1989)

3: Weiss (1980)

4: Dalmazzone (1995)

The Exp column lists the experimental lower flammability limits.

For both criteria $C 1$ and $C 4$, the Pred column gives the predicted value, and the Err column the difference between predicted and experimental values. 
(pure air) to $x=$ stoichiometric mole fraction, and depends on the parameters $\Delta^{0}{ }_{c} H, M_{F}$ and $n_{F}$, which are all properties of the fuel. That particular value, noted $C^{*} i$, taken by the criterion $C i_{(i=1,4)}$ at the exact mole fraction $x$ corresponding to the lower flammability limit, may be considered as the frontier between non-hazardous and hazardous mixtures. In the following, we assume that these values $C^{*} i$ are independent of the nature of the fuel. Therefore, the prediction of the lower flammability limit of a given fuel in air is equivalent to the determination of the mole fraction $x$ corresponding to $C i=C^{*} i$. Given the fuel properties, $x$ is expressed by the following equations:

- first criterion, from Relation (1), it comes:

$$
x=\frac{C^{*} 1 \times 28.84}{\Delta_{c}^{0} H-C^{*} 1 \times\left(M_{F}-28.84\right)}
$$

- fourth criterion, Relation (2) gives:

$$
\begin{aligned}
& x^{2}\left[\left(M_{F}-28.84\right)\left(n_{F}-2\right)-10 \frac{\left(\Delta_{c}^{0} H\right)^{2}}{C^{*} 4}\right] \\
& \quad+x\left[2\left(M_{F}-28.84\right)+28.84\left(n_{F}-2\right)\right]+2 \times 28.84=0
\end{aligned}
$$

The positive root of this equation is the fuel mole fraction that corresponds to $C 4=C^{*} 4$.

The aim of the optimisation was to find the values $C^{*} 1$ and $C^{*} 4$, that give statistically the best estimates of flammability limits, by minimising the standard error of the 67 predicted limits:

$$
\left(\frac{1}{66}\right)^{1 / 2}\left(\sum_{67} E r r^{2}-\frac{1}{67}\left(\sum_{67} E r r\right)^{2}\right)^{1 / 2}
$$

where Err stands for the estimation error: predicted limit experimental limit. For each criterion, the following iterative process was applied:

- choosing a value $C^{*} i$

- computing the 67 estimates using the proper equation, and the 67 estimation errors;

- computing the standard deviation;

- going back to the first step until a minimum is found.

\section{RESULTS AND DISCUSSION}

The complete set of molecules is listed in Table 1, together with the experimental and predicted limits. The results are summarised in Table 2, in which each row corresponds to one criterion. The first column contains the optimal value of $C * i$, the second and third columns give the average absolute error and the standard deviation of the estimates. The fourth and fifth columns give the minimum and the maximum error observed.

Lower flammability limits predicted using $C 4$ are statistically lower than those obtained with $C 1$, by $0.04 \mathrm{~mol} \%$ on average. This is confirmed by the histogram in Figure 1, which presents the distribution of the two series of estimates in seven classes of error. With both criteria, 65 estimates over 67 have a deviation comprised between -0.5 and $+0.1 \mathrm{~mol} \%$. $C 1$ estimates are in majority (37 over 67 ) precise to $\pm 0.1 \mathrm{~mol} \%$, while the majority (35 over 67) of $C 4$ estimates have a negative deviation of -0.3 to $-0.1 \mathrm{~mol} \%$. Only acetylene has its lower limit overestimated by more than $0.5 \mathrm{~mol} \%$, the error being slightly greater using $C 1$ than using $C 4$.

\subsection{Precision and Reliability of the Method}

Experimental limits are usually known with a precision of only $0.1 \mathrm{~mol} \%$. Furthermore, values reported by diverse

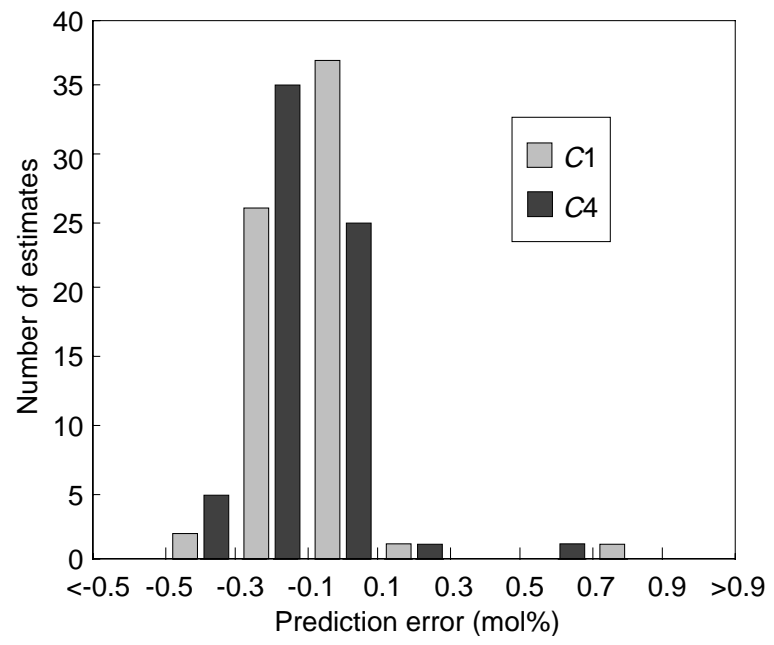

Figure 1

Distribution of prediction errors.

Estimation results

\begin{tabular}{c|c|c|c|c}
\hline Criterion & Average prediction error (mol\%) & Standard deviation (mol\%) & Most negative error (mol\%) & Most positive error (mol\%) \\
\hline$C * 1=-0.345$ & -0.07 & 0.14 & -0.31 & +0.80 \\
$C * 4=15.1$ & -0.11 & 0.14 & -0.34 & +0.65 \\
\hline
\end{tabular}


sources often differ by several tenths of a mole percent for the same fuel. The precision of the predictive method is thus comparable to most experimental determinations.

Hilado (1975) and Hilado and Cumming (1979), who described one of the most precise predictive methods of flammability limit estimation, reported a standard deviation of $0.26 \mathrm{~mol} \%$ for a set of compounds of carbon, hydrogen and oxygen. This may be compared to the standard deviation of our estimates $(0.14 \mathrm{~mol} \%)$.

The reliability of the estimates depends not only on the standard deviation, but also on the sign of the errors. A negative error means that non-flammable mixtures will be considered as flammable, resulting in an excess of cautiousness. A positive error means exactly the opposite, resulting in potentially dramatic consequences. For safety purposes, it is always preferable to overestimate the hazard. Therefore, $C 4$ can be considered as the best of CHETAH criteria for predicting the lower flammability limits of hydrocarbons in air.

\subsection{Application to Fuel Mixtures}

It is easy to apply this method to the prediction of flammability limits of fuel mixtures. The thermal hazard criteria of a fuel blend mixed with air at lean concentration may be obtained using Equations (1) and (2) as well as for pure fuels. The following equations may be used in that case to compute the required data:

$$
\begin{gathered}
\Delta_{c}^{0} H=\sum_{i} v_{i} \Delta_{c}^{0} H_{i} \\
M_{F}=\sum_{i} v_{i} M_{i} \\
n_{F}=\sum_{i} v_{i} n_{i}
\end{gathered}
$$

where $v_{i}$ stands for the mole fraction of fuel $i$ in the blend. Using these definitions, we implicitly assume that the fuels behave as ideal gases, neglecting excess properties such as enthalpies of mixing.

When dealing with fuels having close properties and chemical structures, such as mixtures of hydrocarbons, the additive law known as Le Chatelier's law (Cleuet and Gros, 1989) allows to compute flammability limits of mixtures, given the individual limits of each fuel:

$$
L=\frac{1}{\sum_{i} \frac{v_{i}}{L_{i}}}
$$

where $L_{i}$ stands for the individual flammability limit of fuel $i$, expressed in the same unit as $L$. Le Chatelier's law is useful for predicting both lower and upper flammability limits of any mixture of several fuels with a single oxidiser. The results are generally better for lower limits.
Le Chatelier's law is based on the assumption that flammability limits are additive properties. In other words, mixing in any proportion several gas mixtures, each of them being composed of air and a fuel at its exact limit concentration, at given temperature and pressure, should result in a mixture whose concentration is equal to the blend's flammability limit, at the same temperature and pressure. Because the data used to compute the hazard criteria are also defined by additive relations in Equations (3), (4) and (5), applying the thermochemical method to fuel mixtures should logically be equivalent to applying Le Chatelier's law, using predicted values as individual limits.

We can easily demonstrate this equivalence for criterion $C 1$. From Equations (1), (3) and (4), it comes:

$$
\frac{1}{x}=\frac{\sum_{i} v_{i} \Delta_{c}^{0} H_{i}-C^{* 1}\left(\sum_{i} v_{i} M_{F i}-28.84\right)}{28.84 \cdot C^{* 1}}
$$

By definition $\sum_{i} v_{i}=1$, thus:

$$
\frac{1}{x}=\frac{\sum_{i} v_{i} \Delta_{c}^{0} H_{i}-C^{* 1}\left(\sum_{i} v_{i} M_{F i}-\sum_{i} v_{i} \cdot 28.84\right)}{28.84 \cdot C^{* 1} 1}
$$

leading to:

$$
\frac{1}{x}=\sum_{i} v_{i} \frac{\Delta_{c}^{0} H_{i}-C^{* 1}\left(M_{F i}-28.84\right)}{28.84 \cdot C^{* 1}}
$$

If we represent the predicted limit of each fuel $i$ alone in air by $x_{i}$, this is equivalent to:

$$
\frac{1}{x}=\sum_{i} \frac{v_{i}}{x_{i}}
$$

And finally:

$$
x=\frac{1}{\sum_{i} \frac{v_{i}}{x_{i}}}
$$

which is the same as Equation (6).

For the estimates computed using criterion $C 4$, the equivalence with Le Chatelier's law can be illustrated graphically. As an example, Figure 2 reports three sets of estimates of lower flammability limits for a mixture of 1-hexane and 1-nonane in air, at $25^{\circ} \mathrm{C}$ and $1 \mathrm{~atm}$. The first set, represented by a dashed line, was obtained using Le Chatelier's law with the experimental values as individual limits, that is, respectively for 1-hexane and 1-nonane, 1.18 and $0.83 \mathrm{~mol} \%$ in air. The second set, represented by a solid line, was obtained using Le Chatelier's law with the values predicted using criterion $C 4$ as the individual limits: 1.06 and 


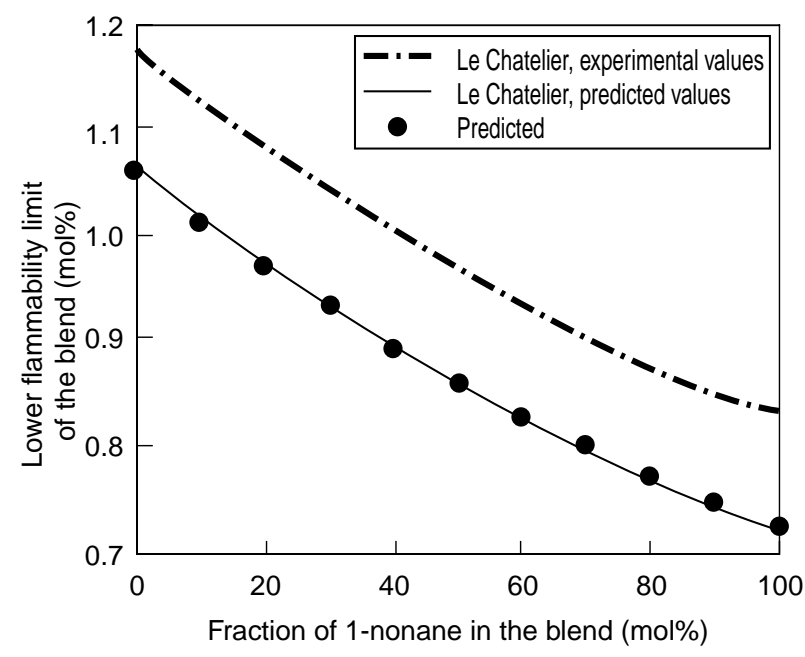

Figure 2

Lower flammability limit estimates of blends of 1-hexane and 1-nonane in air.

$0.72 \mathrm{~mol} \%$, respectively. The third set, represented by points, was obtained using $C 4$ to estimate the flammability limit of each blend, from pure hexane to pure nonane with a step of $10 \mathrm{~mol} \%$. It is obvious that the second and third sets of estimates are equivalent.

\section{CONCLUSION}

A new method for predicting the lower flammability limits of hydrocarbon gases and vapours in air, at atmospheric pressure and ambient temperature, has been developed. It uses the fourth thermochemical hazard criterion of ASTM program CHETAH as a flammability criterion. All data necessary to the criterion computation may be obtained from the chemical structure of the compound, by the Benson's group contribution method. As the Benson's contributions for hydrocarbon groups are all well known, the method can be predictively applied to virtually any hydrocarbon molecule and mixture. It is consistent with the additive rule of Le Chatelier, usually used to compute the flammability limits of mixtures.

The method is more precise than the most accurate predictive methods already existing. Also, the estimates are on average slightly lower than the experimental limits, which is preferable for safety purposes.

\section{ACKNOWLEDGEMENT}

The authors wish to thank the INRS for its financial support to this study.

\section{REFERENCES}

Benson, S.W. (1976) Thermochemical Kinetics, 2nd ed., John Wiley \& Sons, New York.

Cleuet, A. and Gros, P. (1989) Les mélanges explosifs. INRS ED 335, Institut national de recherche et de sécurité, Paris.

Coward, H.F. and Jones, G.W. (1952) Limits of Flammability of Gases and Vapours. Bulletin 503, US Bureau of Mines.

Dalmazzone, D. (1995) Essai d'estimation prédictive des limites d'inflammabilité des vapeurs organiques : exploitation de critères thermochimiques d'explosivité. PhD Thesis, université de Technologie de Compiègne.

Ducros, M., Gruson, J.F. and Sannier, H. (1981) Méthode d'estimation des limites d'inflammabilité. Thermochimica Acta, 48 3, 351-359.

Ducros, M. and Sannier, H. (1988) Application du programme CHETAH à l'étude de la sensibilisation de composés oxygénés et à l'estimation des limites inférieures d'inflammabilité. Journal of Hazardous Materials, 19, 1, 33-49.

Hilado, C.J. (1975) A Method for Estimating Limits of Flammability. Journal of Fire and Flammability, 6, 130-139.

Hilado, C.J. and Cumming, H.J. (1979) Limits of Flammability of Organic Chemicals. Journal of Fire and Flammability, 10, 252-260.

Pedley, J.B., Naylor, R.D. and Kirby, S.P. (1986) Thermochemical Data of Organic Compounds, 2nd ed., Chapman and Hall, London.

Seaton, W.H., Freedman, E. and Treweek, D.N. (1974) CHETAH: The ASTM Chemical Thermodynamics and Energy Hazard Evaluation Program. ASTM Data Series Publication DS 51, American Society for Testing and Materials, Philadelphia.

Shebeko, Y.N., Ivanov, A.V. and Dmitrieva, T.M. (1983) Methods of Calculation of Lower Concentration Limits of Combustion of Gases and Vapours in Air. The Soviet Chemical Industry, 15, 3, 311-314.

Shimy, A.A. (1970) Calculating Flammability Characteristics of Hydrocarbons and Alcohols. Fire Technology, 6, 2, 135-139.

Wagman, D.D., Evans, W.H., Parker, V.B., Schumm, R.H., Halow, I., Bailey, S.M., Churney, K.L. and Nuttall, R.L. (1982) The NBS Tables of Thermochemical Properties. Journal of Physical and Chemical Reference Data, 11, Supp. 2.

Weiss, G. (1980) Hazardous Chemicals Data Book, Noyes Data Corporation.

Zabetakis, M.G. (1965) Flammability Characteristics of Combustible Gases and Vapours. Bulletin 627, US Bureau of Mines.

Final manuscript received in May 2001 